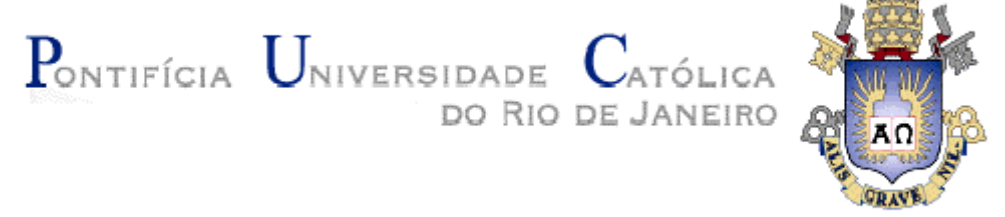

Ana Maria Bastos Loureiro

\title{
Práticas de Leitura e Escrita em uma escola \\ na contemporaneidade: o manuscrito, o impresso e o digital
}

Tese de Doutorado

Tese apresentada ao Programa de Pós-Graduação em Educação do Departamento de Educação da PUC-Rio como parte dos requisitos parciais para obtenção do título de Doutor em Educação.

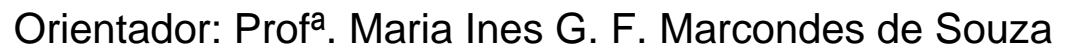

Co-orientador: Prof. ${ }^{a}$ Tania Dauster Magalhães e Silva

Rio de Janeiro

Abril de 2009 
Ana Maria Bastos Loureiro

\section{Práticas de Leitura e Escrita em uma escola na contemporaneidade: o manuscrito, o impresso e o digital}

Tese apresentada como requisito parcial para obtenção do título de Doutor pelo Programa de Pós-Graduação em Educação do Departamento de Educação do Centro de Teologia e Ciências Humanas da PUC-Rio. Aprovada pela Comissão Examinadora abaixo assinada.

Prof ${ }^{\text {a }}$. Maria Ines G. F. Marcondes de Souza Orientadora Departamento de Educação - PUC-Rio

Prof ${ }^{a}$. Tania Dauster Magalhães e Silva Co-orientadora Departamento de Educação - PUC-Rio

Prof $^{\mathrm{a}}$ Isabel Alice Oswald Monteiro Lelis Departamento de Educação - PUC-Rio

Prof $^{\mathrm{a}}$. Angela Maria de Randolpho Paiva Departamento de Sociologia e Política - PUC-Rio

Prof $^{a}$. Maria Teresa de Assunção Freitas UFJF

Prof $^{a}$. Maria de Lourdes Rangel Tura UERJ

Prof. Paulo Fernando C. de Andrade Coordenador Setorial do Centro de Teologia e Ciências Humanas Rio de Janeiro, 06 de abril de 2009 
Todos os direitos reservados. É proibida a reprodução total ou parcial do trabalho sem autorização da universidade, da autora e do orientador.

\section{Ana Maria Bastos Loureiro}

Graduou-se em Letras pela Universidade de Brasília (UnB), fez especialização em Educação no curso "Currículo e Prática Educativa” pela Pontifícia Universidade Católica do Rio de Janeiro (PUC-Rio), Mestrado em Educação pela Universidade Católica do Rio de Janeiro (PUC-Rio). Atualmente trabalha como Coordenadora de Segmento do Colégio Santo Inácio do Rio de Janeiro e participa como pesquisadora do GEALE (Grupo de Estudos de Antropologia da Leitura e da Escrita) coordenado pela professora Dra. Tânia Dauster.

Ficha Catalográfica

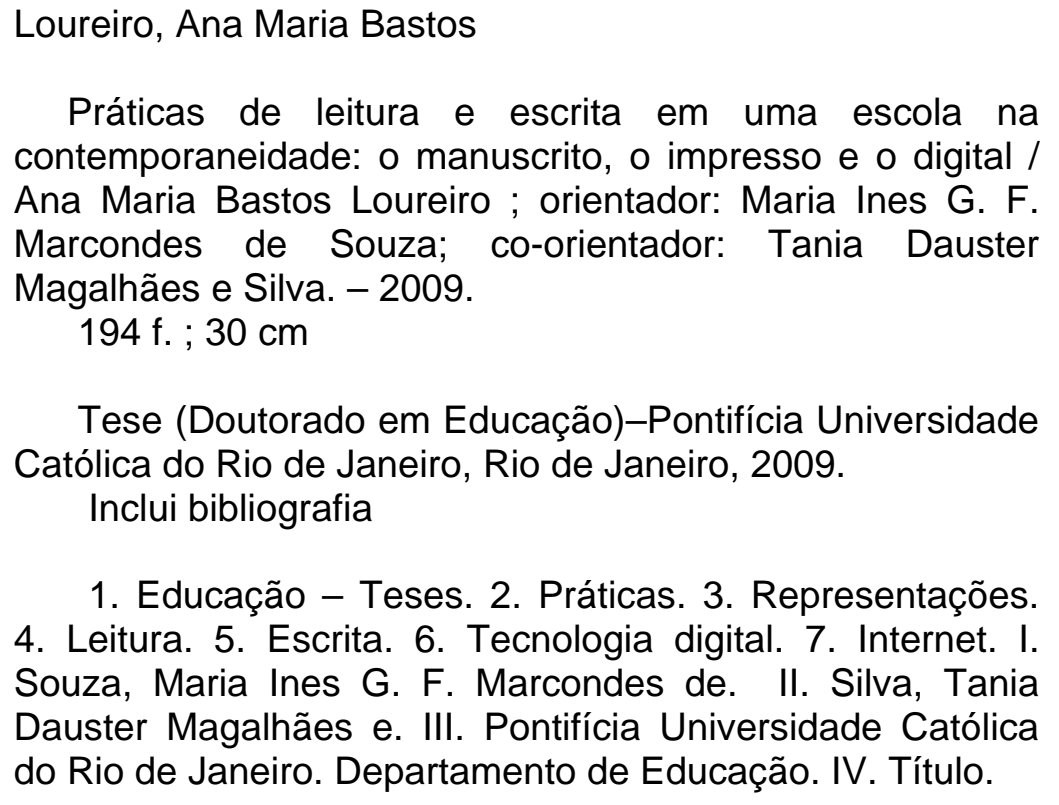

Tese (Doutorado em Educação)-Pontifícia Universidade Católica do Rio de Janeiro, Rio de Janeiro, 2009.

Inclui bibliografia

1. Educação - Teses. 2. Práticas. 3. Representações. 4. Leitura. 5. Escrita. 6. Tecnologia digital. 7. Internet. I. Souza, Maria Ines G. F. Marcondes de. II. Silva, Tania Dauster Magalhães e. III. Pontifícia Universidade Católica do Rio de Janeiro. Departamento de Educação. IV. Título. 
Para meus pais Carlos (in memorian) e Lourdes.

Para meus filhos Liliana e Bernardo.

Para minha neta Joana que está chegando.

Para os educadores do primeiro segmento do Colégio Santo Inácio que me ensinaram a aprender com a alegria das crianças. 


\section{Agradecimentos}

Aos meus filhos e à minha mãe pela paciência e compreensão.

À Maria Inês Marcondes, minha orientadora, pela acolhida amiga e pela confiança.

À Tânia Dauster, pela orientação rica e carinhosa, pelo incentivo de todas as horas.

À Vice-Reitoria Acadêmica da PUC-Rio pela concessão da bolsa.

Aos professores do Departamento de Educação da PUC-Rio pela competência, por tudo o que me ensinaram e pelo apoio em todos os momentos de minha caminhada.

Aos funcionários da Secretaria do Departamento de Educação - Janaína, Neiva, Patrícia, Geneci, Marcelo, Sandra e Nanci - pela ajuda e gentileza.

Ao Professor Gilberto Velho, por me aceitar em sua turma do Programa de PósGraduação em Antropologia Social da UFRJ.

À Direção do Colégio santo Inácio, na pessoa do Exmo. Reitor Pe. Paulo de Arruda D’Elboux, SJ., pelo apoio e incentivo.

Ao Professor Georges Fredéric Mirault, coordenador do ensino médio do Colégio Santo Inácio, pela amizade e por me abrir as portas de seu segmento. 
Aos professores e alunos do ensino médio dessa instituição pela paciência e por disponibilizar seu tempo para tantas conversas, entrevistas e momentos de aula.

Aos professores e funcionários do primeiro segmento do colégio, principalmente as assessoras pedagógicas Mariza Guina e Ângela Barroso, as orientadoras Andreia Salomão, Cristina Espanha, Letícia Coelho, Liliani Hucke, Mariza Freitas e Sônia Prado, e à responsável pela secretaria desse segmento, Maria Fernanda Almeida. Esse trabalho só foi possível porque pude contar com a colaboração e apoio de cada uma de vocês.

Ao Marcos Paulo Vitoriano de Medeiros, funcionário do Núcleo de Mídia do colégio, pela grande ajuda nas gravações das entrevistas.

Ao amigo Jorge Dau pela ajuda inestimável na escrita do 'abstract'.

À minha amiga de todas as horas, Angelice Marins de Farias Barcellos, pela generosidade sempre presente.

Ao meu querido amigo, Alberto José da Costa Tornaghi (Bebeto), pelas trocas indispensáveis, pelos socorros inadiáveis nos momentos mais cruciais, pelo incentivo e carinho. Agora podemos escrever juntos... 


\section{Resumo}

Loureiro, Ana Maria Bastos; Marcondes, Maria Inês. Práticas de Leitura e Escrita em uma escola na contemporaneidade: o manuscrito, o impresso e o digital. Rio de Janeiro, 2009, 194 p. Tese de Doutorado - Departamento de Educação, Pontifícia Universidade Católica do Rio de Janeiro.

Esta tese objetivou descrever as práticas leitoras e escritoras de professores e estudantes do Ensino Médio de uma escola da rede particular de ensino localizada na zona sul da cidade do Rio de Janeiro, tendo como pano de fundo o mundo contemporâneo com seus desafios e demandas, assim como as implicações dele decorrentes na educação e, especificamente, na escola. As práticas, sejam elas sociais, políticas, culturais ou escolares, só têm importância na medida em que produzem sentido, o sentido que lhes atribuem os sujeitos que delas se apropriam, gerando diferentes interpretações. As questões que permearam o percurso da pesquisa buscaram descobrir os significados que emergiram dessas práticas, as representações produzidas por elas, e como essas práticas foram construídas histórica e socialmente. Nesse sentido, optei por uma pesquisa qualitativa de cunho etnográfico como abordagem teórico-metedológica em que observação participante e entrevistas semi-estruturadas se impuseram como principais ferramentas. É mister perceber que as questões apresentadas interessam tanto à História Cultural, a história das práticas de leitura e escrita, quanto à Antropologia. Outras questões emergiram no bojo da análise dessas práticas quanto à percepção da escola nos dias atuais, principalmente no que concerne às novas formas de pensar e conceber o conhecimento diante dos avanços das novas tecnologias, e a como situá-la, assim como seus sujeitos, diante das exigências do mundo contemporâneo. Como esses atores se comportam frente aos recursos disponibilizados na era digital, como utilizam as ferramentas dessa rede mundial de comunicação e informação e o que pensam dessa revolução tecnológica que nos coloca diante do novo e do imprevisto foram também questões postas neste trabalho de pesquisa.

\section{Palavras-chave}

Práticas; Representações; Leitura; Escrita; Tecnologia Digital; Internet. 


\section{Abstract}

Loureiro, Ana Maria Bastos; Marcondes, Maria Inês (Advisor). Reading and writing practices in a contemporary school: handwriting, print and digital. Rio de Janeiro, 2009, 194 p. Thesis - Departamento de Educação, Pontifícia Universidade Católica do Rio de Janeiro.

This thesis intends to describe the reading and writing practices of High School teachers and students in a private school located in Rio de Janeiro's south zone, in face of contemporary world's challenges and demands, as well as its consequences in education and, specifically, at the school. These practices, whether they are social, politic or at the school environment, are important only as far as they make sense, the sense that is given to them by the subjects that take them up for themselves, generating different interpretations. The questions that permeated the development of this research tried to figure out the meaning of these practices, the representations they produced, and how these practices were built, historically and socially. In this sense, I chose to use the qualitative research, of ethnographic bias, as the theoretical-methodological approach, in which the participating observation and semi-structured interviews imposed themselves as the main tools. It is fundamental to perceive that these questions pertain to the History of the Cultures, the history of the reading and writing practices, as well as to Anthropology. Other questions appeared in the middle of the analysis of these practices, in terms of the perception one has of the school nowadays, mainly trying to identify how the development of new technologies influences how we think and conceiving knowledge, as well as how the school and its subjects position themselves on the subject of the contemporary's world demands. The way these actors behave when facing the resources of the digital era, how they use the World Wide Web communication and information tools, and what they think of this technological revolution makes us face the new and the unforeseen, were some questions also present in this research.

\section{Keywords}

Practices; Representation; Reading; Writing; Digital Technologies; Internet. 


\section{Sumário}

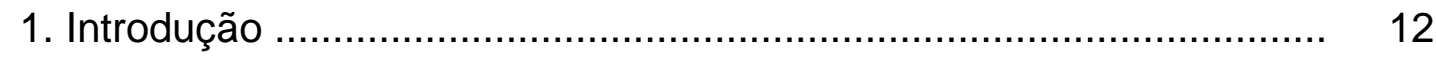

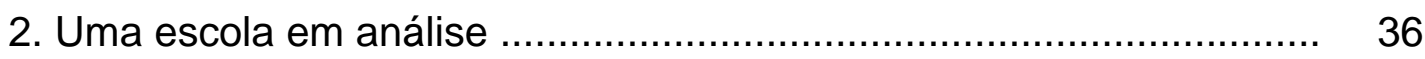

2.1. Reflexões sobre a escola .................................................. 37

2.2. Entrando em campo: uma escola particular ............................. 40

2.3. Aspectos estruturais ............................................................. 43

2.4. A identidade ......................................................................... 46

2.5. Concluindo capítulo ................................................................ 53

3. Professores e alunos: reflexões contemporâneas sobre a escola ..... 54

3.1. Reinventar a escola: escolhas possíveis .................................. 54

3.2. Professores e alunos: algumas percepções ............................... 60

3.3. Concluindo o capítulo ................................................... 66

4. A Leitura e a Escrita nas múltiplas práticas escolares .................... 67

4.1. As práticas "relacionais" .................................................... 68

4.2. As práticas "didáticas" ........................................................ 77

4.2.1. As aulas ................................................................. 77

4.2.2. A biblioteca .......................................................... 88

4.3. Concluindo o capítulo ................................................ 92 
5. A Leitura e a Escrita de professores e alunos ................................. 93

5.1. Leitura e escrita: um recorte teórico …………………………..... 94

5.2. A Leitura em seus diversos suportes ........................................ 98

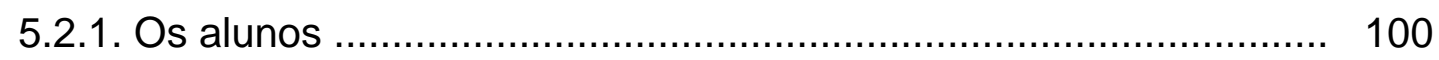

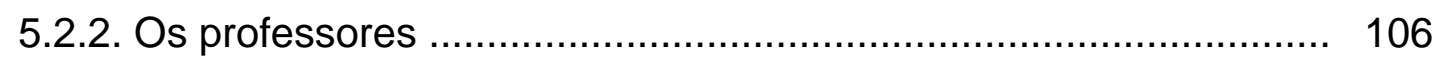

5.3. A Escrita em seus diversos suportes ...................................... 110

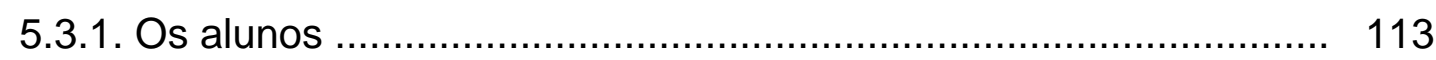

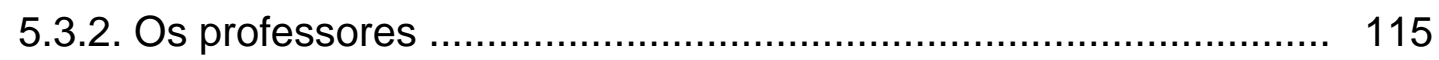

5.4. E a Língua Portuguesa? ....................................................... 117

5.5. Concluindo o capítulo ………………………....................... 123

6. As novas tecnologias e a escola na contemporaneidade ................. 124

6.1. O mundo contemporâneo: um panorama ..................................... 125

6.2. E as novas tecnologias, o que são? ......................................... 132

6.3. Professores, alunos e as NTICS ............................................ 138

6.4. E a formação dos professores em NTICS, aconteceu? .................. 142

6.5. Concluindo: intuições sobre o futuro .......................................... 147

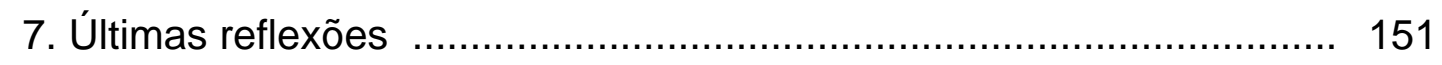

8. Referências Bibliográficas ....................................................... 158

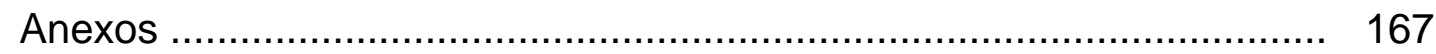




\section{A Moda Terminal}

\section{Zuenir Ventura}

Já declararam o fim da memória, da escrita, da pintura, da fotografia, do teatro, do rádio, das ferrovias, da História e já anunciaram até que o mundo ia se acabar. Todos os que previram esses desfechos chegaram ao fim antes. Agora, a moda é decretar que o jornalismo está terminando (e o livro também). Citam "New York Times", "Washington Post”, "Le Monde”, "Newsweek” como alguns dos veículos com sérias dificuldades financeiras. Reconheço que há argumentos respeitáveis e indícios preocupantes. Mas vamos relativizar o pânico. No Brasil, por exemplo, nos dois últimos anos, a circulação dos diários cresceu. Em 2007, enquanto a expansão mundial não passou de $2,5 \%$, aqui foi de $11,8 \%$.

Desconfio muito das antecipações feitas por um mundo que não conseguiu prever nem a crise econômica atual. Além do mais, nunca antes na História - como diz aquele que já aboliu os jornais de sua vida - uma nova tecnologia de comunicação eliminou a anterior. Com o advento da escrita - para citar a primeira dessas transformações - acreditava-se que, por desuso, a memória iria desaparecer. Dispondo de um suporte mecânico para registrar suas experiências, o homem não usaria mais a cabeça. Para que decorar, se era possível guardar tudo em forma de letrinhas? (a última especulação no gênero é a de que o Google vai tornar inúteis arquivos e bibliotecas).

Antes se dizia que a "civilização visual” (a TV) iria abolir a "civilização verbal”. Uma imagem vale mais que mil palavras, repetia-se, esquecendo-se de que só se diz isso com palavras. Agora se afirma, veja a ironia, que a internet veio salvar a escrita que a TV estava matando. De fato, nunca se escreveu tanto quanto hoje, pelo menos em e-mails. A onipresença desse universo online passou então a funcionar como uma espécie de pá de cal sobre o jornal. Só que a internet ainda precisa da confirmação e do endosso do "impresso", de seu prestígio e credibilidade. Pergunte a um divulgador o que ele prefere para seu contratado, uma página na internet ou uma notinha no Ancelmo ou no Gente Boa? Os blogueiros sérios que me perdoem, mas a rede não é confiável (ainda bem para Veríssimo e Jabor, pelo que costumam atribuir a eles ali). Uma vez, um site noticiou que eu tinha morrido. Houve controvérsia, mas eu só não morri mesmo porque a notícia não saiu nos jornais.

Por tudo isso, é provável que, em vez de extermínio, haja convergência de mídias, como já está ocorrendo. Muitos dos blogs e sites mais influentes estão hospedados em jornais e revistas.

O Globo, Opinião, 14 de fevereiro de 2009, p:07 